\title{
Remote Sensing of the Atmosphere for Environmental Assessment and National Security
}

\author{
J.D. Molitoris \\ D. Venable \\ E. Davis \\ J.F. Arens \\ A. Farah
}

June 10, 1999

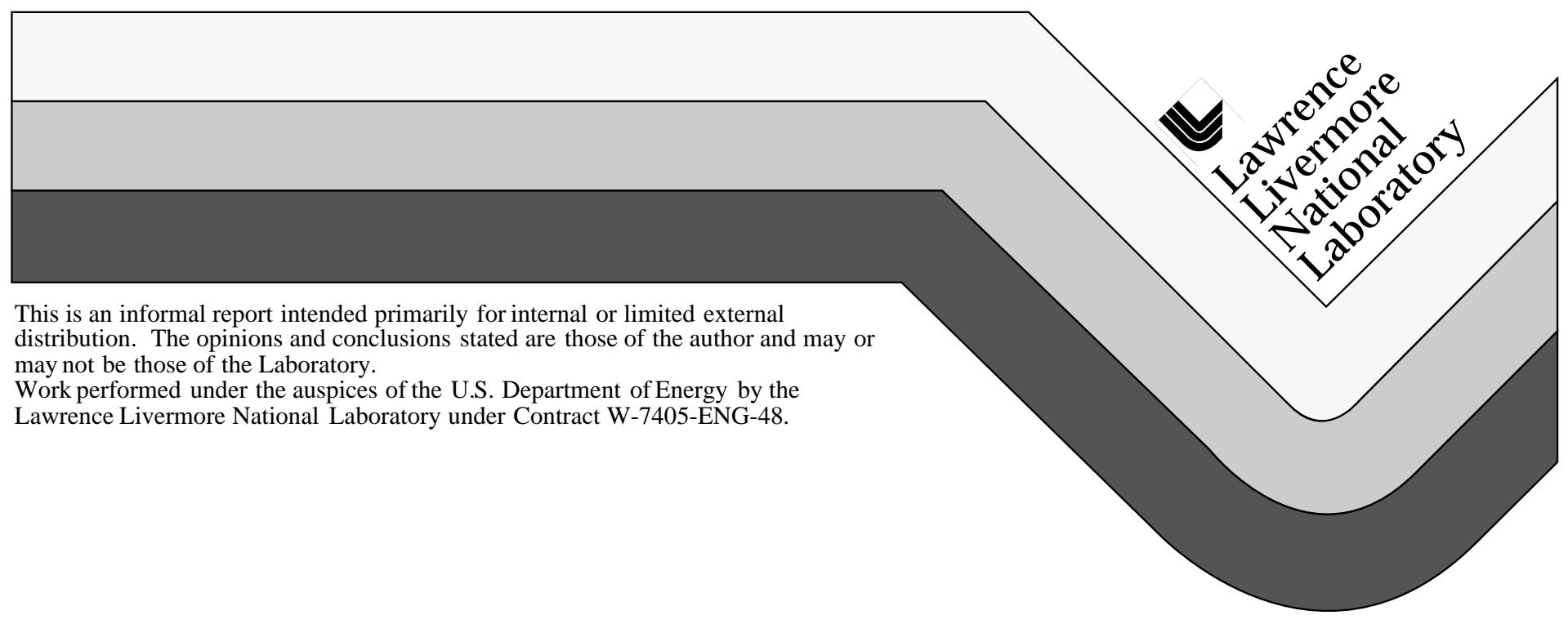




\section{DISCLAIMER}

This document was prepared as an account of work sponsored by an agency of the United States Government. Neither the United States Government nor the University of California nor any of their employees, makes any warranty, express or implied, or assumes any legal liability or responsibility for the accuracy, completeness, or usefulness of any information, apparatus, product, or process disclosed, or represents that its use would not infringe privately owned rights. Reference herein to any specific commercial product, process, or service by trade name, trademark, manufacturer, or otherwise, does not necessarily constitute or imply its endorsement, recommendation, or favoring by the United States Government or the University of California. The views and opinions of authors expressed herein do not necessarily state or reflect those of the United States Government or the University of California, and shall not be used for advertising or product endorsement purposes.

This report has been reproduced directly from the best available copy.

Available to DOE and DOE contractors from the Office of Scientific and Technical Information P.O. Box 62, Oak Ridge, TN 37831

Prices available from (423) 576-8401

Available to the public from the National Technical Information Service

U.S. Department of Commerce 5285 Port Royal Rd. Springfield, VA 22161 


\title{
Remote Sensing of the Atmosphere for Environmental Assessment and National Security
}

Principal Investigators: John Molitoris (LLNL) and Demetrius Venable (Howard University)

LLNL Collaborators: Eric Davis

U.C. Collaborators: J.F. Arens

Students: Ahmed Farah (Howard University)

\begin{abstract}
The research performed this year marked the beginning of a collaboration between Howard University and LLNL to advance and apply remote sensing technology to a broad range of applications centered on probing the state of the atmosphere. Central to this research was the evolution of a telescope facility at Howard University into an atmospheric observatory and instrument development test-bed. Our work in applying laser technology to remote sensing helped lead to the development and subsequent patent application of a laser heterodyne amplifier and progress toward the development of a multi-wavelength laser probe to determine the range resolved size distribution of particulate matter and aerosols in the atmosphere. Work performed this year also helped us motivate further studies to understand atmospheric radiance and radiation transport in threedimensions. Our involvement in these programs as supported by the LLNL Research Collaborations Program for Historically Black Colleges and Universities is reported here.
\end{abstract}

\section{Objectives}

The research performed under this contract is related to an ongoing experimental program in Remote Sensing and Environmental Measurements within the Health and Ecological Assessment Division at LLNL. The objectives under this contract are to apply laser technology to key issues in remote sensing, form a better understanding of atmospheric radiation transport in three dimensions, and explore the utility of detailed atmospheric remote sensing in the vicinity of major metropolitan areas to determine the value of such measurements for environmental studies regarding pollutants and the detection / tracking / dispersion of hazardous agents released into the atmosphere. 


\section{Progress}

\section{Applications of Lasers to Remote Sensing}

The laser is an ideal tool to perform columnar range resolved measurements of the atmosphere [1]. Such laser remote sensing is called lidar, for light detection and ranging. In general there are two types of lidars centering on direct or indirect detection of the return signal and both techniques are being implemented in this project.

The indirection detection lidar being developed improves upon a heterodyne technique which mixes a sample of the outgoing beam with the return signal $[2,3]$. The resulting frequency analyzed spectrum clearly illustrates any shift between the two signals. As this lidar utilizes very narrow line-width lasers $(<5 \mathrm{KHz}$ over $1 \mathrm{~ms})$ which have large coherence lengths, it can be used to measure motion up to distances of $30 \mathrm{~km}$ away. As our goal is to use this lidar to understand turbulence in the boundary layer by measuring the motion of entrained particulates and aerosols with high spatial and temporal resolution [4], we concentrated on increasing the sensitivity of the heterodyne receiver. Higher sensitivity detection also enables the use of lower power lasers. Research for this project helped lead to the development of a cavity re-injection technique [5] which can increase the sensitivity up to a factor of 1000 over normal laser Doppler volocimetry and decrease sampling time to $<1 \mathrm{~ms}$.

This technique requires further refinement, but we have started to test it for wind sensing. Figure 1 shows a comparison of the wind velocity between the lidar and a calibrated air velocity transducer. The agreement is very good, but there is more work to be done to translate this instrument into a field unit for boundary layer turbulence studies. Advances in this type of lidar can be applied to any type of remote sensing requiring high sensitivity motion detection. In fact, as the return signal strength increases as the size of the object being detected is increased, aerosol / particle detection is the most stringent test of this lidar.

We also started to develop direct detection backscatter lidar [1] for atmospheric constituent analysis. Unlike the instrument described above, this lidar directly detects backscattered photons. Single wavelength backscatter lidars can be used to detect and quantify structure in the atmosphere such as pollution layers or sub-visible clouds. Our work with this lidar is leading to the development of a multiple wavelength backscatter system to not only determine concentration, but particle size distribution. The multi-wavelength approach will allow us to extract the moments of the size distribution as a function of range. The key questions are how many wavelengths are necessary and how well can we calibrate the instrument. Calibration can be performed in the remote sensing laboratory at LLNL using 
a 3 meter test cell to set up a known aerosol/particle distribution. The calibration translates to improved accuracy in field measurements which are performed at the Howard University Atmospheric Observatory (HUAO). The pilot data shown below is taken with a single wavelength backscatter lidar. These data show fine scale structure as well as multiple layers in descending cirrus clouds. The range resolution here is $24 \mathrm{~m}$ with a temporal resolution of 30 seconds.

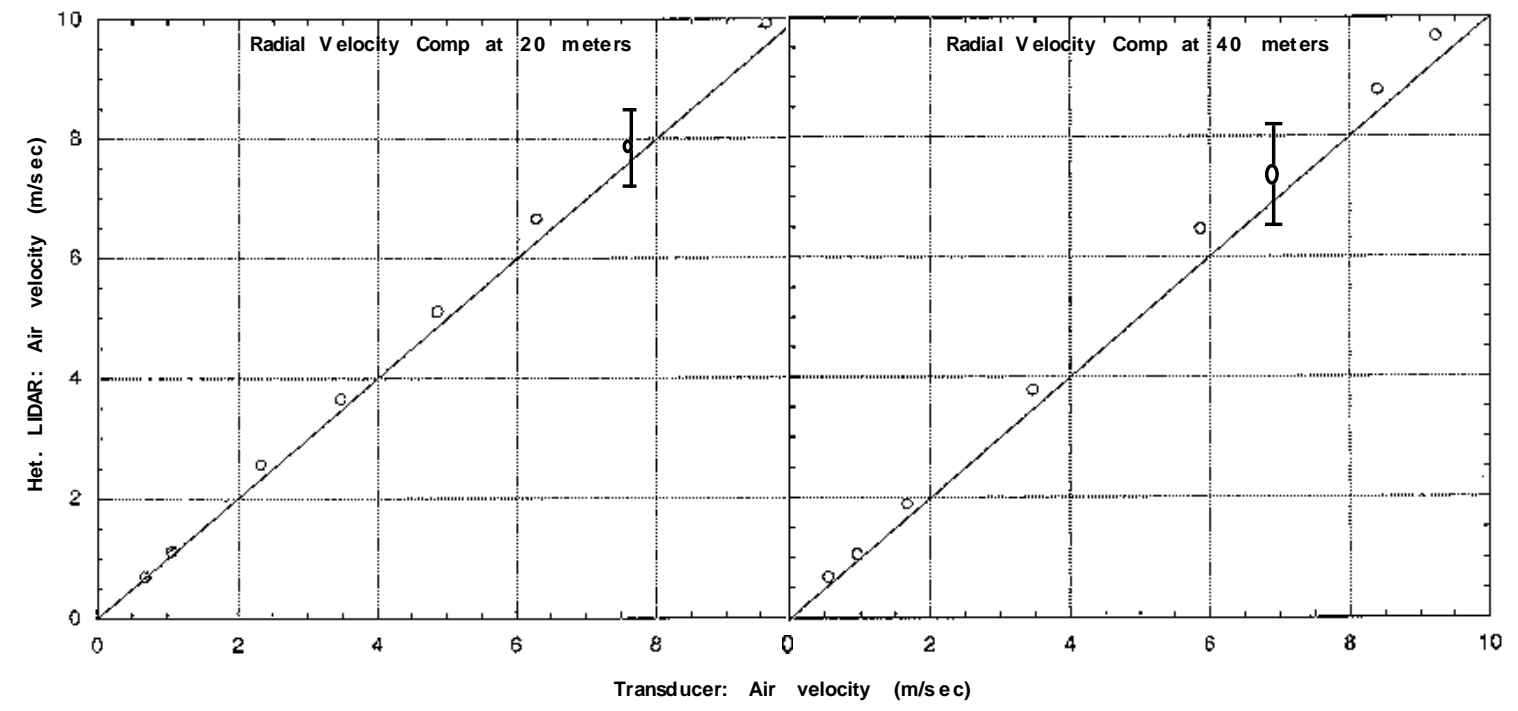

Figure 1. The radial velocity is the component parallel to the laser probe beam. The data shows a comparison between the lidar and a calibrated transducer of a controlled ambient air jet at two distances. Each data point required only a 15 micro second sampling time. Largest error is shown. 


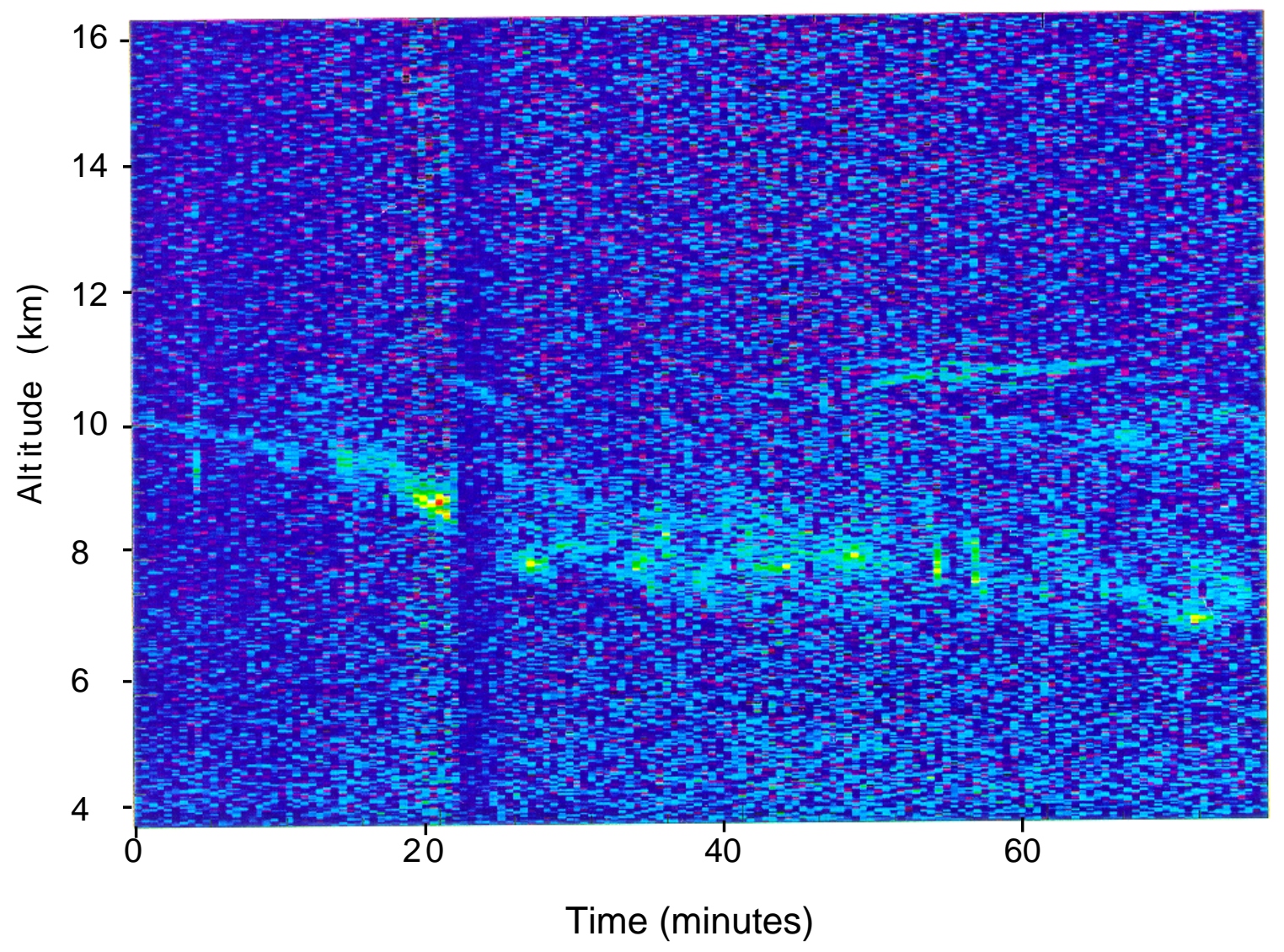

Figure 2. Single wavelength backscatter lidar data as a function of time illustrates the instruments ability to see through cirrus clouds and to altitudes of $16 \mathrm{~km}$. Our research is improving upon this type of lidar to also determine the size distribution of the scatterers.

\section{Atmospheric Radiance and Radiation Transport in 3-D}

Although the computing power is available, atmospheric radiation transport modeling in three-dimensions is far from being well developed. In fact, the development of 3-D transport models requires a high degree of validation and comparison with field data. Such field data must be spectrally resolved and be able to take narrow columnar measurements while the sky dome is being monitored for changes in the cloud field. In order to better understand atmospheric radiation transport in a real three-dimensional world we are outfitting three instruments for a field experiment to be run at the HUAO. These include a UV/optical spectrometer with a spectral range from 0.2 to 1.2 microns, an infrared imaging spectrometer with a spectral range of 2.0 to 28 microns, and a whole sky imaging (WSI) system. The optical spectrometer is nearly ready for field measurements. The observational set-up is illustrated in figure 3 below which shows the whole sky dome. 


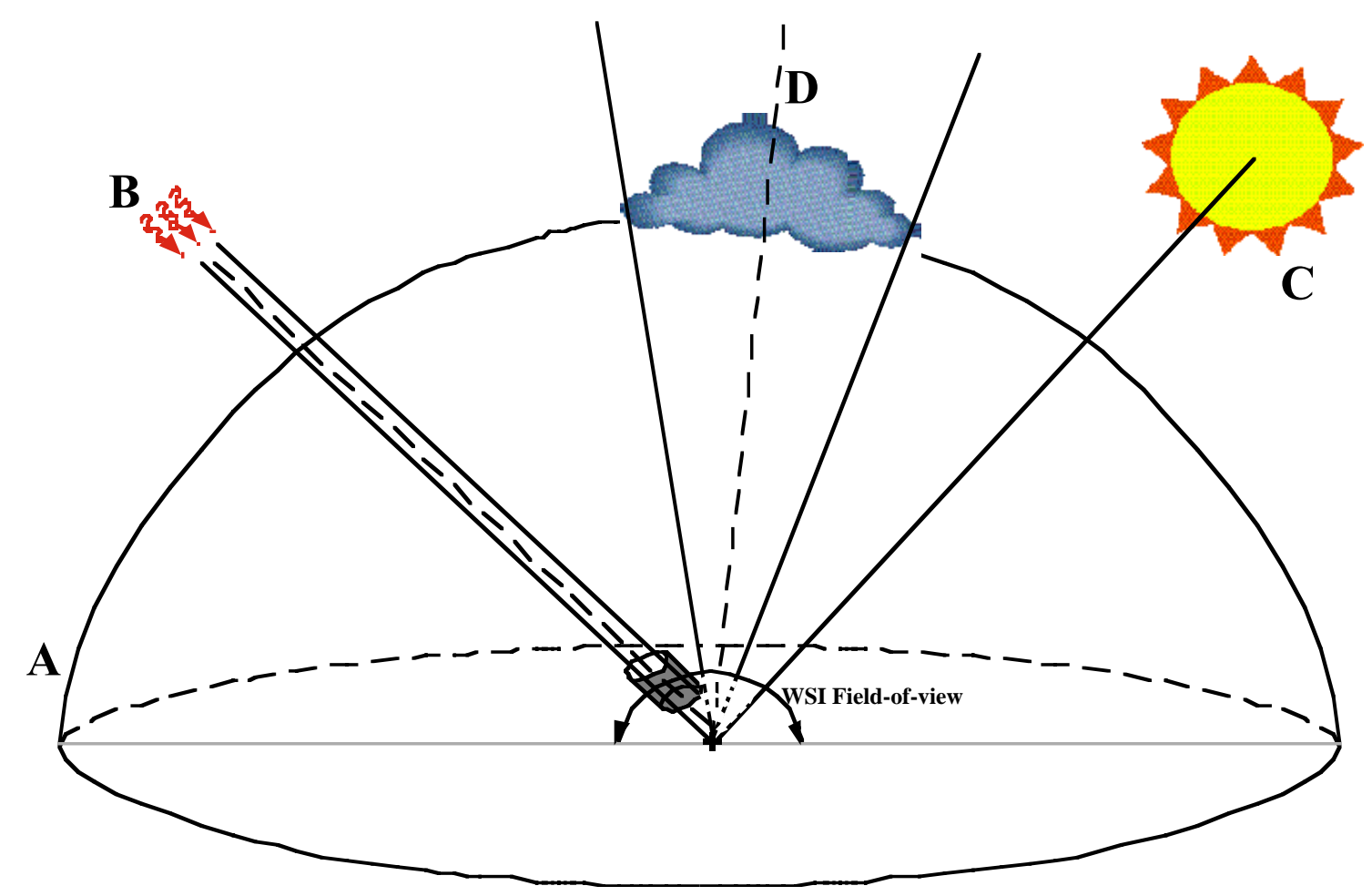

Figure 3. Schematic of full sky dome imaged by the WSI to determine clocations of clouds and the sun. The spectrally resolved data is taken in a narrow column with either a dual Cassagrain UV/Optical spectrometer or an IR imaging spectrometer.

Here the WSI determines the angular relationship of objects within the dome to the columnar $(<0.25$ degree) spectral measurement. The spectral irradiance of direct sunlight after it passes through the earth's atmosphere is clearly affected by absorption and falls within the envelope of the calculated black body irradiance. This is always true for a true clear sky measurement, but three dimensional effects from clouds (scattering) manifest as excursions beyond the expected black body limit. Our experiment will quantify these features and relate them to cloud and cloud field properties. This experiment/field study is part of a student PhD thesis (A. Farah) on atmospheric radiance. This year we re-outfitted and began testing two of the three required instruments. Once the optical spectrometer and WSI are fielded at the HUAO, the Spectrally resolved IR imager will be readied.

\section{Observational facility and Remote Sensing / Instrument Development Test-bed}

All of the sensor development cited above relates to a common goal. The wind measurements are necessary to determine atmospheric transport, aerosol concentration and size affect atmospheric chemistry, and the 
anomalous absorption in the measured radiance allows the identification and concentration determination of foreign agents in the atmosphere. The progress we made this past year in active and passive remote sensor development is focused on performing atmospheric measurements for environmental science and national security [6]. The test site for these measurements is a telescope facility in Beltsville, MD which this contract is helping evolve into the Howard University Atmospheric Observatory cited above [7]. Development of the HUAO is an ongoing effort supported by Howard University through the Dept. of Physics and Astronomy. The core of our Howard - LLNL collaboration is the merging of LLNL's remote sensing expertise and laboratory facilities with the field measurement capabilities of the HUAO. The location of the HUAO (shown in the map below, figure 4) is ideally situated between Washington, D. C. and Baltimore, MD for measurements relating strongly to both metropolitan regions.

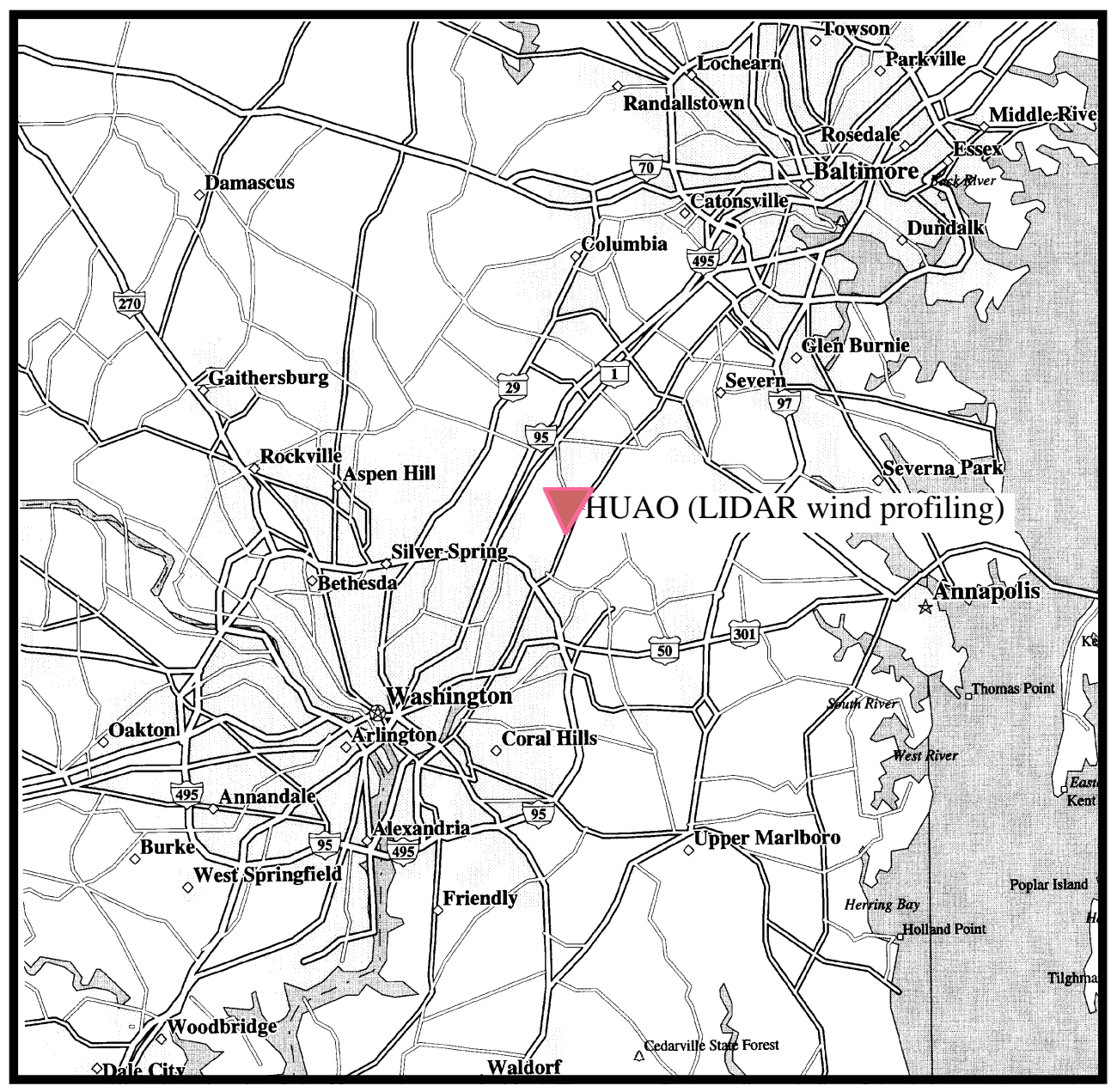

Figure 4. Location of the HUAO in the Washington / Baltimore area. 
The rolling topography of the region makes the site ideal for the collection of wind and pollution data important to both cities. Furthermore, range resolved wind data from the HUAO is an essential element for high accuracy estimates of the dispersion and flow of possible atmospheric releases of hazardous materials including chemical, biological, and radiological agents. Due to the national significance of this area, our atmospheric research and field data will impact the mitigation of the possible threat of terrorist activity and can be used to improve simulations in this area.

In addition to remote sensor progress, much progress was also made on the HUAO in order to prepare for our field observations. This collaboration helped upgrade the optics of the 30" telescope and devise a computer control system for the facility which will be implemented in 1998. In progress are also a beam transport system from the support building into the telescope dome and a data acquisition system for the multiple sensor observations. Associated funds from Howard University were also used to upgrade the physical plant of the HUAO and make general improvements. The telescope dome and primary support building of the HUAO is shown below (figure 5).

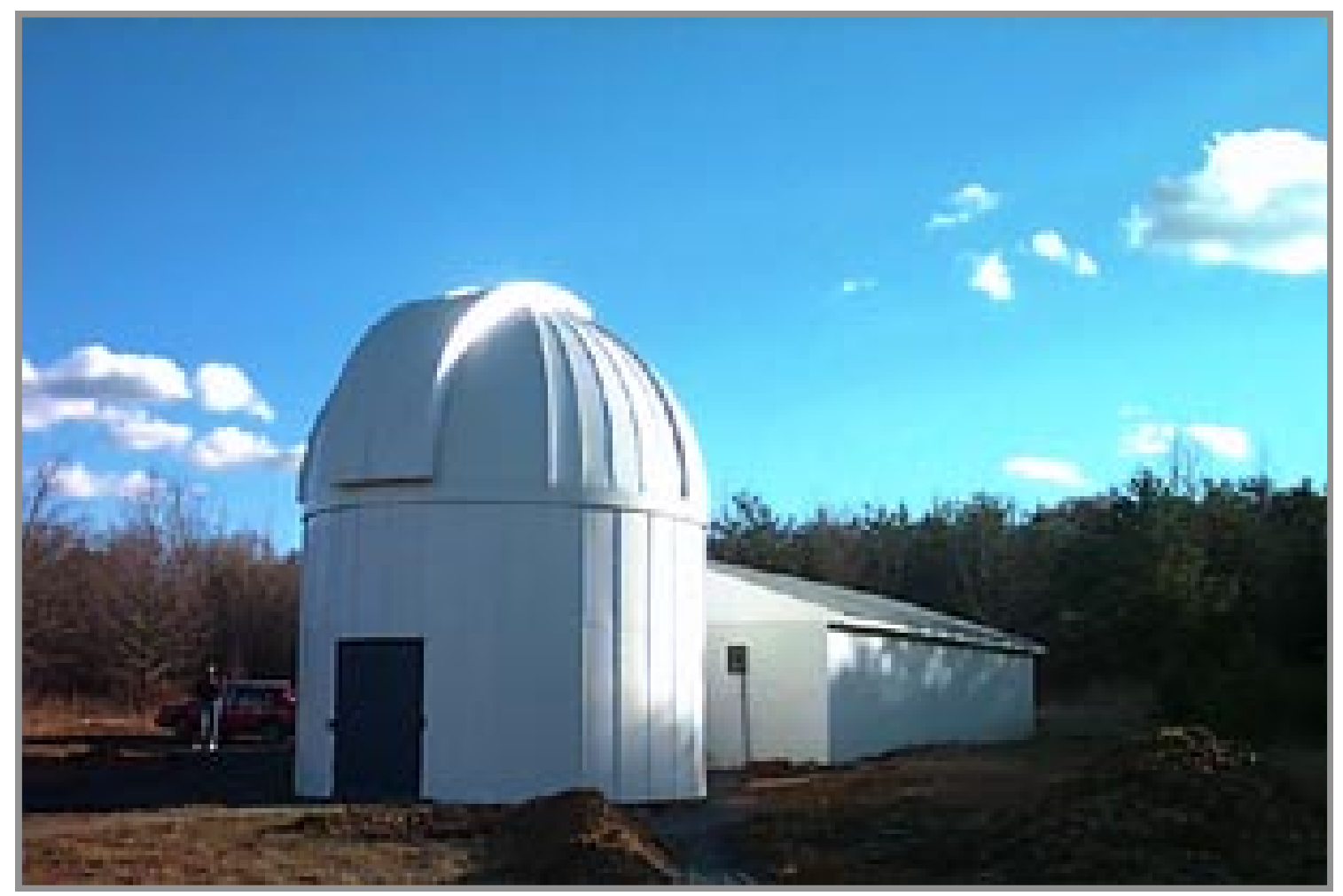

Figure 5. The HUAO is the field station being used for this project. Shown is the telescope dome and support building located at the Howard University Research Park in Beltsville, MD. 


\section{$\underline{\text { References }}$}

1) R. M. Measures, "Laser Remote Sensing, Fundamentals and Applications", Krieger Publishing Co., Malabar, Florida, 1992.

2) S. G. Peglow and J. D. Molitoris, "Pre/Post-Strike Atmospheric Assessment System", UCRL-ID-126733, February 3, 1997.

3) J. D. Molitoris, E. I. Davis, J. F. Arens, D. D. Venable, "Development of a Portable Wind Sensing LIDAR," Fall 1996 Meeting of the AGU, San Francisco, CA (UCRL-JC-125075 Abs).

4) J. D. Molitoris, E. I. Davis, D.D. Venable, A. Farah, “Development of a LIDAR for Aerosol and Turbulence Measurements in the Boundary Layer," Spring 1997 Meeting of the AGU, Baltimore, MD (UCRL-JC-126755 Abs).

5) J. D. Molitoris, "Cross-Cavity Re-Injection for Laser Heterodyne Amplification"; DOE Invention Case No.: S-88,556 (RL-13974); LLNL Invent. Docket No.: IL-10163; Inventor: John D. Molitoris. Date Disclosed: April 25, 1997, Patent Applied for: August 13, 1997.

6) J. D. Molitoris, E. I. Davis, S.G. Peglow, D. D. Venable, P. E. Smith, "Development of Emplaced Sensors for Atmospheric Assessment," SPIE AeroSense '97 Symposium, Conference on Peace and Wartime Applications and Technical Issues for Unattended Ground Sensors, Orlando, FL (UCRL-JC127310 Abs).

7) D. D. Venable, A. Farah, J. D. Molitoris, E. I. Davis, “Development of an Atmospheric Observatory for Research in Remote Sensing," Spring 1997 Meeting of the AGU, Baltimore, MD (Submitted by Howard Univ.) 


\title{
Publications, Abstracts, and Patents Produced by the 1996-97 Research Collaborations Program through this Project
}

\author{
Abstracts / Papers
}

J. D. Molitoris, E. I. Davis, J. F. Arens, D. D. Venable, “Development of a Portable Wind Sensing LIDAR," Fall 1996 Meeting of the AGU, San Francisco, CA (UCRL-JC-125075 Abs).

J. D. Molitoris, E. I. Davis, D.D. Venable, A. Farah, “Development of a LIDAR for Aerosol and Turbulence Measurements in the Boundary Layer," Spring 1997 Meeting of the AGU, Baltimore, MD (UCRL-JC-126755 Abs).

J. D. Molitoris, E. I. Davis, S.G. Peglow, D. D. Venable, P. E. Smith, "Development of Emplaced Sensors for Atmospheric Assessment," SPIE AeroSense '97 Symposium, Conference on Peace and Wartime Applications and Technical Issues for Unattended Ground Sensors, Orlando, FL (UCRL-JC127310 Abs).

D. D. Venable, A. Farah, J. D. Molitoris, E. I. Davis, “Development of an Atmospheric Observatory for Research in Remote Sensing," Spring 1997 Meeting of the AGU, Baltimore, MD (Submitted by Howard Univ.)

\section{Patent(s)}

J. D. Molitoris, "Cross-Cavity Re-Injection for Laser Heterodyne Amplification"; DOE Invention Case No.: S-88,556 (RL-13974); LLNL Invent. Docket No.: IL-10163; Inventor: John D. Molitoris. Date Disclosed: April 25, 1997, Patent Applied for: August 13, 1997.

This work was performed under the auspices of the U.S. Dept. of Energy at LLNL under contract no. W-7405-Eng-48. 